\title{
Shifting crop planting calendar as a climate change adaptation solution for rice cultivation region in the Long Xuyen Quadrilateral of Vietnam
}

\author{
Dang Truong $\mathrm{An}^{1^{*}}$ \\ ${ }^{1}$ Ton Duc Thang University, Faculty of Environment and Labour Safety, Sustainable Management of Natural Resources and Environment \\ Research Group, Ho Chi Minh City-070000, Vietnam. "Corresponding author (dangtruongan@tdtu.edu.vn).
}

Received: 22 April 2020; Accepted: 21 July 2020; doi:10.4067/S0718-58392020000400468

\begin{abstract}
Rice (Oryza sativa L.) paddies in the Long Xuyen Quadrilateral Region of Vietnam have regularly met the increased risks under the impacts of climate change (ICC), resulting in a decline in crop productivity. The objective of this study was to determine the suitable times for broadcasting rice crops in the rice cultivation paddies belonging to Long Xuyen Quadrilateral as a mitigation solution to the negative ICC. To conduct this research, crop model namely the FAO-AquaCrop (Version 6.0) was selected to simulate grain yields of rice crops based on different scenarios of crop broadcasting calendar (CBC). The results point out that the grain yield of winter-spring (WS) and summer-autumn (SA) cropping seasons can increase up to $6.2 \%$ and $5.3 \%$ if the $\mathrm{CBC}$ is delayed from 7 to $14 \mathrm{~d}$ compared to the current broadcasting calendar (baseline) in the two experimental areas while the grain yield of the autumn-winter (AW) cropping season can increase $6.4 \%$ if the $\mathrm{CBC}$ is shifted $14 \mathrm{~d}$ compared to the baseline. In general, a shift in the $\mathrm{CBC}$ for all rice broadcasting crops compared to the baseline can be considered as an effective solution to minimize the negative impacts of weather factors as well as contribute to improve rice productivity.
\end{abstract}

Key words: Climate change, crop model, grain yield, Oryza sativa, shift.

\section{INTRODUCTION}

In recent years, precipitation has strongly varied in many areas of the world (MNRE, 2016; Lee and Dang, 2019c), resulting in drought often appear in the dry season, flooding occur in the wet season (Asia Pacific Network, 2010; MNRE, 2016), and off-season precipitation leading to rice crop failure (Asia Pacific Network, 2010; Lee and Dang, 2020). Kotir (2011) stated that the potential risks for agriculture sector under the impacts of climate change (ICC) are attracting the attention of mankind in the $21^{\text {st }}$ century. According to Ministry of Natural Resources and Environment (MNRE, 2016), Vietnam is valued as one of the top countries which will be seriously affected by climate change. The Consultative Group for International Agricultural Research (CGIAR) Research Program on Climate Change, Agriculture and Food SecuritySoutheast Asia (CGIAR-CCAFS SEA, 2016) identified that climate change will strongly affect many parts of Asia in the $21^{\text {st }}$ century, especially agricultural drought and off-season precipitation are expected to increase in frequency and intensity. CGIAR-CCAFS SEA (2016) has also predicted that approximately 7.2\% of agricultural land area of Vietnam will be impacted by agricultural drought and saline intrusion as part of climate change.

Climate change is expected to shift in the crop broadcasting calendar (CBC) in many regions of the world (Kim et al., 2013; Deb et al., 2016; Adnan et al., 2017). Therefore, determination of the right time for broadcasting crop season will help to mitigate the adverse impacts as well as contribute to improve crop productivity (Jaliya et al., 2008; Deb et 
al., 2016). As a recognition of the importance of determining the appropriate time to broadcast rice crops in the context climate change, studies on shift in the CBC have conducted in many countries around the world (Jibrin et al., 2012; Deb et al., 2016; Babel et al., 2019). For example, a study on CBC and cultivar effect on dryland maize production conducted by Kamara et al. (2009) reported that selection of the suitable cultivars and right time for broadcasting crop seasons contribute to increase crop productivity. Dharmarathna et al. (2014) conducted a study on a shift in the CBC for four rice varieties sown in Kurunegala District of Sri Lanka. Their results carried out that the grain yield of dry season would increase compared to the base condition if the $\mathrm{CBC}$ is delayed $30 \mathrm{~d}$ for all four broadcasting varieties under two scenarios, A2 and B2. A study on the rice yield in Ca Mau Province of Vietnam under the ICC and brackish irrigation water carried out by Deb et al. (2016). They reported that a decline in the grain yield varying from $1.6 \%$ to $23.6 \%$ compared to the baseline for A2 scenario is recorded of the summer-autumn (SA) cropping season. Shrestha et al. (2016) investigated the ICC on rice (Oryza sativa L.) yield of the winter-spring (WS) and SA cropping seasons and proposed several adaptation solutions to overcome the negative ICC on rice production in Quang Nam Province, Vietnam. Their results stated that a shift in the $\mathrm{CBC}$ combined with supplementary irrigation and proper nutrient management can be suitable rice cultivations in the context of climate change. Further, Wang et al. (2017) investigated the suitable broadcasting crop and fertilizer application rates for two rice cultivars in Cambodia under the ICC. Their results pointed out that a delay in the CBC for two cultivars can achieve the higher yields in the future.

As a useful tool in supporting decision making, crop models such as Crop Syst-Cropping Systems Simulation Model, CERES-Crop Environment Resource Synthesis Sorghum, APSIM-Agricultural Production Systems Simulator, WOFOSTWorld Food Studies Crop Growth Model, CropWat, EPIC-Environmental Policy Integrated Model, SAFYE-Simple Algorithm for Yield-Evapotranspiration, AquaCrop, and ALMANAC-Agricultural Land Management Alternatives with Numerical Assessment Criteria have been commonly applied in many regions of the world (Jibrin et al., 2012; Saab et al., 2015; Yue et al., 2015; Babel et al., 2019). For example, Chatterjee et al. (2012) used the CropWat model (Land and Water Development Division, FAO, Rome, Italy) to simulate irrigation water demand in the Gangetic West Bengal. Dharmarathna et al. (2014) used the DSSAT crop model to study the CBC for four rice varieties sown in Kurunegala District of Sri Lanka. Further, Saab et al. (2015) used the AquaCrop and CropSyst models to predict the growth process and yield. A study on water use requirement in the Ca Mau Peninsula of Vietnam using the FAO-AquaCrop model was conducted by Deb et al. (2016). Wang et al. (2017) used the CERES crop model to define the CBC in Cambodia under the ICC. Cheng et al. (2018) applied the WOFOST model to investigate soil available nutrients in the northeast area of China. Recently, Babel et al. (2019) evaluated the irrigation water demand and manure application rates of maize in the Himalayan Region of India combining the AquaCrop model with DSSAT-CERES model.

The rice paddies in the Long Xuyen Quadrilateral have faced drought, saline intrusion and off-season precipitation events over the last two decades, due to the ICC, resulting in crop yield decline (MNRE, 2016; Lee and Dang, 2020). Farmers must re-broadcast rice crops if a precipitation event with high intensity just occur after the seeds have broadcasted in the rice fields (Deb et al., 2016; Lee and Dang, 2020). Further, in the harvesting stage of the SA cropping season, heavy precipitation events with intensity reach up to $20 \mathrm{~mm}$ appear suddenly, resulting in the obtained crop yield to be strongly decreased (Asia Pacific Network, 2010; Deb et al., 2016). The aim of this work, therefore, was to determine the crop broadcasting calendar using the FAO-AquaCrop model for the main rice crops in the Long Xuyen Quadrilateral to mitigate the negative impacts of weather factors as well as contribute to improve crop productivity.

\section{MATERIALS AND METHODS}

\section{Study area}

Long Xuyen Quadrilateral lies in the northwestern of Mekong Delta (09 $57^{\prime}-10^{\circ} 42^{\prime}$ N, 104 $29^{\prime}-105^{\circ} 29^{\prime}$ E) (Figure 1). Long Xuyen Quadrilateral is one of the two major deltas in the Mekong Delta, with a total of 490000 ha area for agriculture belonging to a part of An Giang, Kien Giang and Can Tho Provinces (Vu et al., 2018; Lee and Dang, 2019c). Yearly, this delta region provides up to 4.9 million tons of rice (Oryza sativa L.), resulting in abundant irrigation water and soil rich in nutrients (Kontgis et al., 2019; Lee and Dang, 2019a). 
Figure 1. Illustration of the study area.

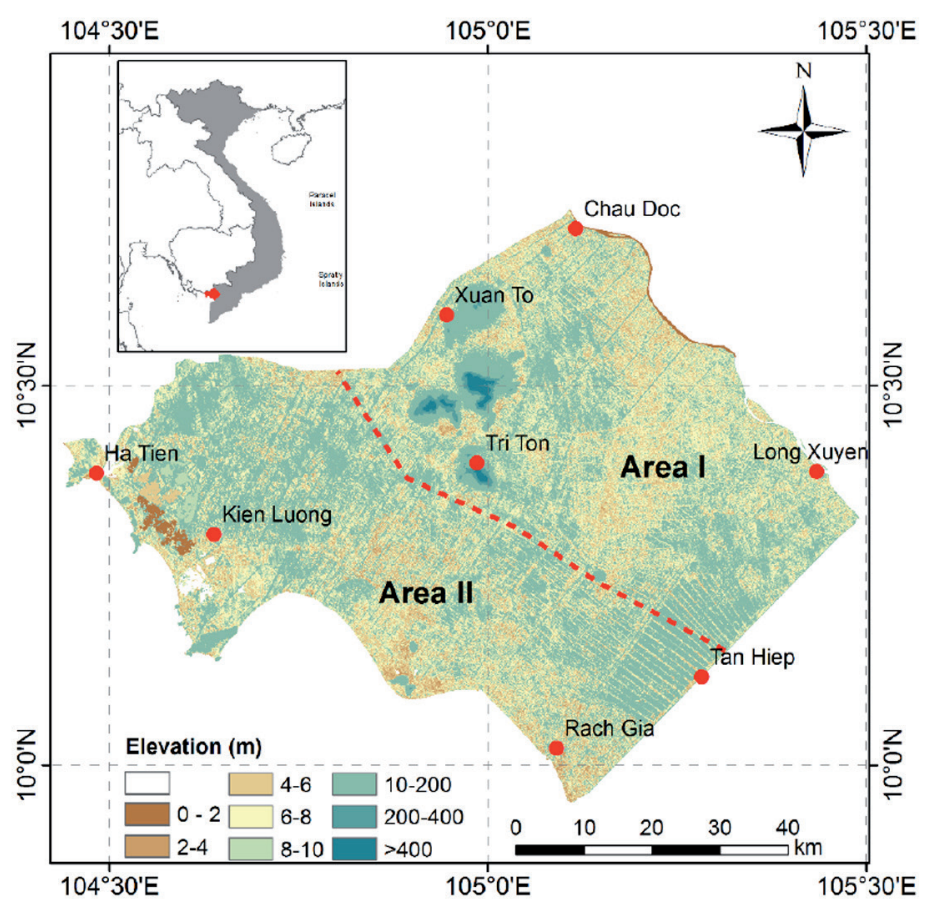

In the Long Xuyen Quadrilateral, rice is broadcasted in the paddies from two to three cropping seasons per year depending on the topographic conditions, irrigation water and local precipitation. The weather condition is consistent for planting rice crops with daily sunshine reach up to $6.3 \mathrm{~h}$, air temperature varies from 27 to $29{ }^{\circ} \mathrm{C}$, mean air humidity reach about $80 \%$ and mean annual precipitation reach approximately $1700 \mathrm{~mm} \mathrm{yr}^{-1}$ (Vu et al., 2018; Lee and Dang, 2020). Rainy season often lasts from mid-May to late November and accounting for $85 \%$ of annual rainfall (Figure 2). Precipitation is not evenly distributed among the sub-regions of the study area. It highly concentrates in the western and southern subregions (Tan Hiep, Ha Tien, Kien Luong and Rach Gia), with values up to $2000 \mathrm{~mm} \mathrm{yr}^{-1}$, while eastern and northern subregions (Chau Doc, Tri Ton, Xuan To and Long Xuyen) receive only approximately $1400 \mathrm{~mm} \mathrm{yr}^{-1}$ (Table 1). According to Lee and Dang (2019c), for the three last decades, a significant change in precipitation has been recorded in the Long Xuyen Quadrilateral. Specifically, a slight upward trend in annual precipitation is recorded in the eastern and northern sub-regions, whereas a significant downward trend is found in the western and southern sub-regions, and this may be negatively impacted, leading to drought and flooding in the Long Xuyen Quadrilateral (Lee and Dang, 2019a; Kontgis et al., 2019). For example, in 2016 and 2019, the two extreme drought events in 90 and 93 yr were recorded in the Mekong Delta, resulting in a widespread irrigation water shortage and seriously hampered for rice paddies in the entire Mekong Delta (CGIAR-CCAFS SEA, 2016; Lee and Dang, 2020). Long Xuyen Quadrilateral has relatively low terrain with ranges from 0.5 to $2.0 \mathrm{~m}$ a.s.1. (Mainuddin et al., 2013; Vu et al., 2018). Therefore, the agricultural activities often face the challenges from salt intrusion due to sea level rise and waterlogging due to heavy precipitation as well as off-season precipitation, as part of climate change (CGIAR-CCAFS SEA, 2016; Deb et al., 2016; Lee and Dang, 2019a). Based on topographical conditions and precipitation distribution, the study area is divided into the two main experiment areas. Specifically, Area I includes Chau Doc, Xuan To, Tri Ton Districts and Long Xuyen City while Area II includes Tan Hiep, Kien Luong, Ha Tien Districts and Rach Gia City (Figure 1). 
Figure 2. Mean monthly precipitation at observation stations in the $19 \mathrm{yr}$ period (2000-2018).

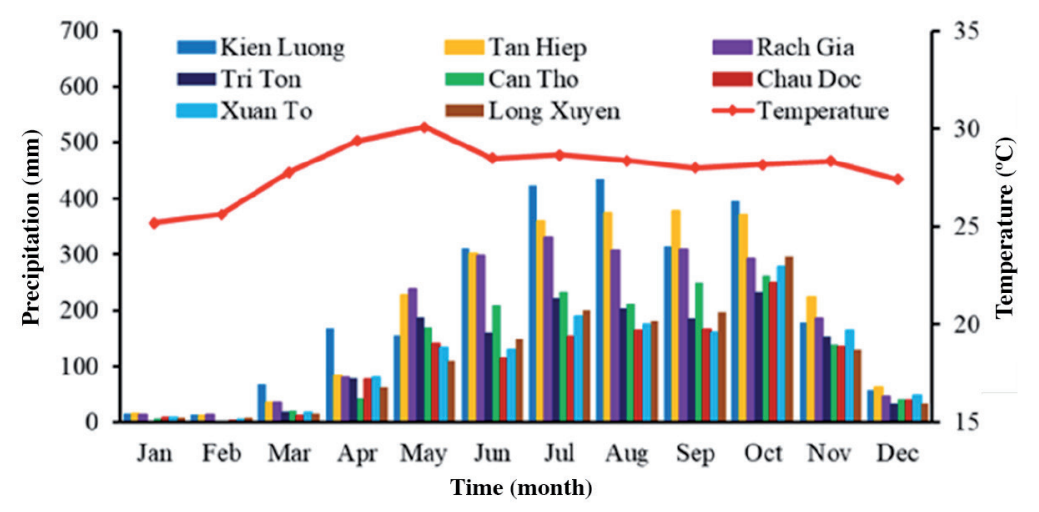

Table 1. Average annual precipitation (AAP) and standard deviation (SD) at observation stations.

\begin{tabular}{lcccc}
\hline Station & AAP & SD & Latitude (N) & Longitude (E) \\
\hline & $\mathrm{mm}$ & $\mathrm{mm}$ & & \\
Chau Doc & 1321.6 & 84.5 & $10^{\circ} 42^{\prime}$ & $105^{\circ} 08^{\prime}$ \\
Tri Ton & 1456.7 & 98.7 & $10^{\circ} 23^{\prime}$ & $104^{\circ} 59^{\prime}$ \\
Xuan To & 1435.8 & 89.9 & $10^{\circ} 35^{\prime}$ & $104^{\circ} 56^{\prime}$ \\
Long Xuyen & 1576.8 & 99.3 & $10^{\circ} 22^{\prime}$ & $105^{\circ} 25^{\prime}$ \\
Tan Hiep & 1698.4 & 105.9 & $10^{\circ} 06^{\prime}$ & $105^{\circ} 16^{\prime}$ \\
Ha Tien & 2643.5 & 145.2 & $10^{\circ} 23^{\prime}$ & $104^{\circ} 29^{\prime}$ \\
Kien Luong & 2205.6 & 139.8 & $10^{\circ} 18^{\prime}$ & $104^{\circ} 38^{\prime}$ \\
Rach Gia & 2098.7 & 137.4 & $10^{\circ} 01^{\prime}$ & $105^{\circ} 05^{\prime}$ \\
\hline
\end{tabular}

\section{FAO-AquaCrop model description}

The FAO-AquaCrop is a crop model which was developed by the Food and Agriculture Organization (FAO). It is assessed as a useful tool for predicting the typical meteorological characteristics such as reference evapotranspiration $\left(\mathrm{ET}_{\mathrm{o}}\right)$, actual evapotranspiration $\left(\mathrm{ET}_{\mathrm{c}}\right)$ and simulating biomass, grain yield of different plant kinds in response to water (Steduto et al., 2009; FAO, 2015). Compared to other crop models, FAO-AquaCrop model requires a significantly smaller number of input data. In the climate module, the FAO-AquaCrop model used the Penman-Monteith formula to calculate ET.

In the FAO-AquaCrop model, $\mathrm{ET}_{\mathrm{o}}$ is calculated as follows:

$$
\mathrm{ET}_{\mathrm{o}}=\frac{0.408 \Delta\left(\mathrm{R}_{\mathrm{n}}-\mathrm{G}\right)+\gamma \frac{900}{\mathrm{~T}+273} \mathrm{u}_{2}\left(\mathrm{e}_{\mathrm{s}}-\mathrm{e}_{\mathrm{a}}\right)}{\Delta+\gamma\left(1+0.34 \mathrm{u}_{2}\right)}
$$

where $R_{n}$ is the net radiation at the soil surface $\left(M J m^{-2} \mathrm{~d}^{-1}\right)$; $\mathrm{G}$ is a soil heat flux density $\left(\mathrm{MJ} \mathrm{m}^{-2} \mathrm{~d}^{-1}\right)$; $\mathrm{T}$ is the average air temperature $\left({ }^{\circ} \mathrm{C}\right) ; \mathrm{u}_{2}$ is wind speed at $2.0 \mathrm{~m}$ height $\left(\mathrm{m} \mathrm{s}^{-1}\right) ; \mathrm{e}_{\mathrm{s}}$ is the saturation vapor pressure $(\mathrm{kPa}) ; \mathrm{e}_{\mathrm{a}}$ is the actual vapor pressure $(\mathrm{kPa}) ; \Delta$ is the slope of the vapor pressure curve $\left(\mathrm{kPa}^{\circ} \mathrm{C}^{-1}\right)$; and $\gamma$ is psychrometric constant $\left(\mathrm{kPa}^{\circ} \mathrm{C}^{-1}\right)$.

Actual evapotranspiration $\left(\mathrm{ET}_{\mathrm{c}}\right)$ is calculated based on $\mathrm{ET}_{\mathrm{o}}$ and the crop coefficient $\left(\mathrm{K}_{\mathrm{c}}\right)(\mathrm{FAO}, 2015)$. $\mathrm{ET}_{\mathrm{c}}$ is calculated as follows:

$$
\mathrm{ET}_{\mathrm{c}}=\mathrm{ET}_{\mathrm{o}} * \mathrm{~K}_{\mathrm{c}}
$$

In the Equation 2, $\mathrm{K}_{\mathrm{c}}$ coefficient is defined depending on each type of the plant and each growth stage.

In the FAO-AquaCrop model, grain yield (GY) is defined as the product of biomass yield $\left(\mathrm{B}_{\mathrm{i}}\right)$ and harvest index $(\mathrm{HI})$ (Jin et al., 2014; FAO, 2015). Grain yield (GY) is calculated as follows:

$$
\mathrm{GY}=\mathrm{B}_{\mathrm{i}} * \mathrm{HI}
$$

where $\mathrm{B}_{\mathrm{i}}\left(\mathrm{kg} \mathrm{ha}^{-1}\right)$ is calculated by $\mathrm{B}_{\mathrm{i}}=\mathrm{WP}^{*} \sum \frac{\mathrm{Tr}_{i}}{\mathrm{ET}_{\mathrm{oi}}}$, WP* is the crop water productivity $\left(\mathrm{g} \mathrm{m}^{-2}\right), \mathrm{Tr}_{\mathrm{i}}$ is the daily crop transpiration $(\mathrm{mm})$, and $\mathrm{ET}_{\mathrm{oi}}$ is the daily $\mathrm{ET}_{\mathrm{o}}(\mathrm{mm})$. While $\mathrm{HI}$ is considered a conservative parameter. In the crop module, $\mathrm{HI}$ is continuously adjusted during grain yield formation. 


\section{Data collection}

In the FAO-AquaCrop model, to simulation run the climate module, meteorological data including solar radiation, sunshine duration, daily maximum and minimum temperatures, relative humidity, wind speed and precipitation is required. In this study, meteorological data at observation stations were collected from the Southern Regional Hydro-meteorological Center of Vietnam (SRHC) in the $19 \mathrm{yr}$ period (2000-2018). Similarly, to simulation run the crop module, information on the soil features such as the moisture content at saturation (SAT), field capacity (FC), permanent wilting point, saturated hydraulic conductivity and total available soil water are required. The analyzed results of the soil features in the surface soil layer $(0-120 \mathrm{~cm})$ applying the Soil Water Characteristics software (Oyeogbe and Oluwasemire, 2013; Silvestro et al., 2017) are presented in Table 2 . To simulation run the crop management module, detailed information about broadcasting and harvesting time, density at broadcasting, and fertilizer application rate are also required. Crop data were obtained from the Department of Agriculture and Rural Development of An Giang, Kien Giang and Can Tho (Table 3). In the Long Xuyen Quadrilateral, the paddies are often broadcasted 'OM6976' in the third week of December and harvested in the first week of April for the winter-spring (WS) cropping season. For the summer-autumn (SA) cropping season, rice is broadcasted in the third week of April and harvested in the fourth week of July while the autumn-winter (AW) cropping season began in the third week of August and ended in the fourth week of December (Table 3). An advantage of 'OM6976' is that it is valued with high productivity, easy to germinate, less pests and a life-cycle varying from 90 to $103 \mathrm{~d}$, depending on local weather conditions.

\section{RESULTS AND DISCUSSION}

\section{Sensitivity analysis}

For almost modelers, sensitivity analysis of the crop models to detect the optimal parameters is considered as a major challenge (Adnan et al., 2017; Silvestro et al., 2017). Sensitivity analysis is commonly conducted to find the optimal values of the key parameters and then they are applied for running simulation the models (Archontoulis et al., 2014; Silvestro et al., 2017). In the FAO-AquaCrop model, the sensitivity of the parameters is appraised and presented in Table 4. The results show that the three key parameter groups found include: high sensitivity (e.g., canopy growth, water stress, length of the flowering stage and harvest index), moderate sensitivity (e.g., canopy decline coefficient, stomatal stress coefficient, water stress coefficient, and base temperature) and low sensitivity (e.g., maximum canopy cover, maximum effective rooting depth, water stress coefficient curve shape, aeration stress coefficient and canopy senescence stress coefficient) (Table 4).

Table 2. Relevant soil characteristics analyzed in the study area.

\begin{tabular}{lc}
\hline Soil description & Values \\
\hline Moisture content at saturation, \% & 47 \\
Field capacity, \% & 32 \\
Permanent wilting point, \% & 20 \\
Saturated hydraulic conductivity, $\mathrm{mm} \mathrm{m}^{-1}$ & 120 \\
Total available soil water, $\mathrm{mm} \mathrm{d}^{-1}$ & 225 \\
Curve number & 46 \\
\hline
\end{tabular}

Table 3. Information about crop calendar, fertilizer schedules and application rate for rice broadcasting crops.

\begin{tabular}{|c|c|c|c|c|c|c|c|c|c|c|c|c|}
\hline \multirow[b]{2}{*}{ Crop } & \multicolumn{2}{|c|}{ Crop calendar } & \multirow{2}{*}{$\begin{array}{l}\text { Rice } \\
\text { variety }\end{array}$} & \multirow{2}{*}{$\begin{array}{l}\text { Density at } \\
\text { broadcast }\end{array}$} & \multirow{2}{*}{$\begin{array}{l}\text { Planting } \\
\text { method }\end{array}$} & \multicolumn{7}{|c|}{$\mathrm{Nr}$ days fertilizer after broadcasting } \\
\hline & Broadcast & Harvest & & & & I & II & III & IV & Urea & NPK & $\mathrm{K}$ \\
\hline & & & & $\mathrm{kg} \mathrm{ha}^{-1}$ & & & & & & & & \\
\hline WS & $20 \mathrm{Dec}$ & $5 \mathrm{Apr}$ & OM6976 & 160 & Broadcast & 8 & 16 & 25 & 40 & 70 & 80 & 50 \\
\hline SA & $20 \mathrm{Apr}$ & $30 \mathrm{Jul}$ & OM6976 & 180 & Broadcast & 8 & 18 & 30 & 45 & 100 & 70 & 50 \\
\hline AW & 20 Aug & 30 Nov & OM6976 & 170 & Broadcast & 8 & 15 & 25 & 38 & 80 & 70 & 50 \\
\hline
\end{tabular}

WS: Winter-spring; SA: summer-autumn; AW: autumn-winter; I, II, III, IV: days after broadcasting. 
Table 4. Sensitivity analysis of the parameters in the FAO-AquaCrop model.

\begin{tabular}{rll}
\hline $\mathrm{Nr}$ & \multicolumn{1}{c}{ Parameters } & Sensitivity level \\
\hline 1 & Base temperature, ${ }^{\circ} \mathrm{C}$ & Moderate \\
2 & Soil water depletion factor for stomatal control & Low \\
3 & Length of the flowering stage, d & High \\
4 & Maximum canopy cover $(\mathrm{CCx})$ & Low \\
5 & Canopy growth coefficient & High \\
6 & Canopy decline coefficient & Moderate \\
7 & Maximum rooting depth & Low \\
8 & Upper threshold water stress coefficient & Moderate \\
9 & Lower threshold water stress coefficient & High \\
10 & Upper threshold of canopy senescence & Moderate \\
11 & Water stress coefficient curve shape & Low \\
12 & Upper threshold stomatal stress coefficient & Moderate \\
13 & Aeration stress coefficient & Low \\
14 & Harvest index of leaf growth before flowering & High \\
15 & Harvest index of leaf growth after flowering & High \\
\hline
\end{tabular}

\section{Performance assessment of the FAO AquaCrop model}

The performance of the crop models was often appraised based on the statistical indicators to evaluate the agreement between the simulated model and observed data (Khov et al., 2017; Lee and Dang, 2019b). In this study, error indices namely coefficient of determination, an index of agreement and root mean square error were used to assess the performance of the FAO AquaCrop model.

Coefficient of determination $\left(\mathrm{R}^{2}\right)$ is calculated as follow:

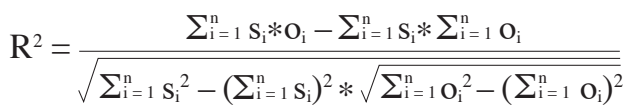

where $\mathrm{S}_{\mathrm{i}}$ and $\mathrm{O}_{\mathrm{i}}$ are the simulated results and observed data, respectively.

The index of agreement (d) is defined by the Equation 5:

$$
\mathrm{d}=1-\frac{\sum_{\mathrm{i}=1}^{\mathrm{n}}\left(\mathrm{s}_{\mathrm{i}}-\mathrm{O}_{\mathrm{i}}\right)^{2}}{\sum_{\mathrm{i}=1}^{\mathrm{N}}\left(\mathrm{S}_{\mathrm{i}}-\overline{\mathrm{O}}_{\mathrm{i}}\right)^{2}}
$$

where $\overline{\mathrm{O}}_{\mathrm{i}}$ is the mean value of $\mathrm{O}_{\mathrm{i}}$ and $\mathrm{n}$ is the number of data points.

Root mean square error (RMSE) is calculated by the Equation 6:

$$
\text { RMSE }=\sqrt{\frac{\sum_{\mathrm{i}=1}^{\mathrm{n}}\left(\mathrm{S}_{\mathrm{i}}-\mathrm{O}_{\mathrm{i}}\right)^{2}}{\mathrm{n}}}
$$

In most practical applications, the RMSE is used as a measure of absolute error between the calculated results and observed data (Khov et al., 2017; Silvestro et al., 2017).

In this work, the FAO-AquaCrop model was calibrated comparing the observed grain yield with simulated results during period $11 \mathrm{yr}$ (2000-2010). The calibrated results indicate that a high correlation (Figures 3a, 3b and 3c) is obtained with $\mathrm{d}=0.81-0.91, \mathrm{R}^{2}=0.88-0.93$ and $\mathrm{RMSE}=0.18-0.43$, respectively (Table 5). The results of model calibration with the high values of $d$ and $\mathrm{R}^{2}$ indices and the low values of RMSE index affirm that the FAO-AquaCrop model is suitable to apply in the Long Xuyen Quadrilateral. Similarly, the FAO-AquaCrop model validation was also conducted comparing the observed grain yield with simulated results in the period of $8 \mathrm{yr}$ (2011-2018). The validated results point out that a good fit is defined between the simulated model and observed grain yield (Figures $3 \mathrm{~d}, 3 \mathrm{e}$ and $3 \mathrm{f}$ ) with $\mathrm{d}=0.84-0.93$, $\mathrm{R}^{2}=0.87-0.95$, and RMSE $=0.19-0.37$, respectively for all rice broadcasting seasons (Table 5). The results of model validation also obtain the high values of $d$ and $\mathrm{R}^{2}$ and the low values of RMSE. Based on the finding, it can affirm that the FAO-AquaCrop model satisfies the evaluation criteria. 
Figure 3. Comparison of simulated and observed grain yield for model calibration of the winter-spring (a), summerautumn (b), autumn-winter (c) cropping seasons in the first experiment (Area I) and winter-spring (d), summer-autumn (e), autumn-winter (f) cropping seasons in the second experiment (Area II) during period 2000-2010.
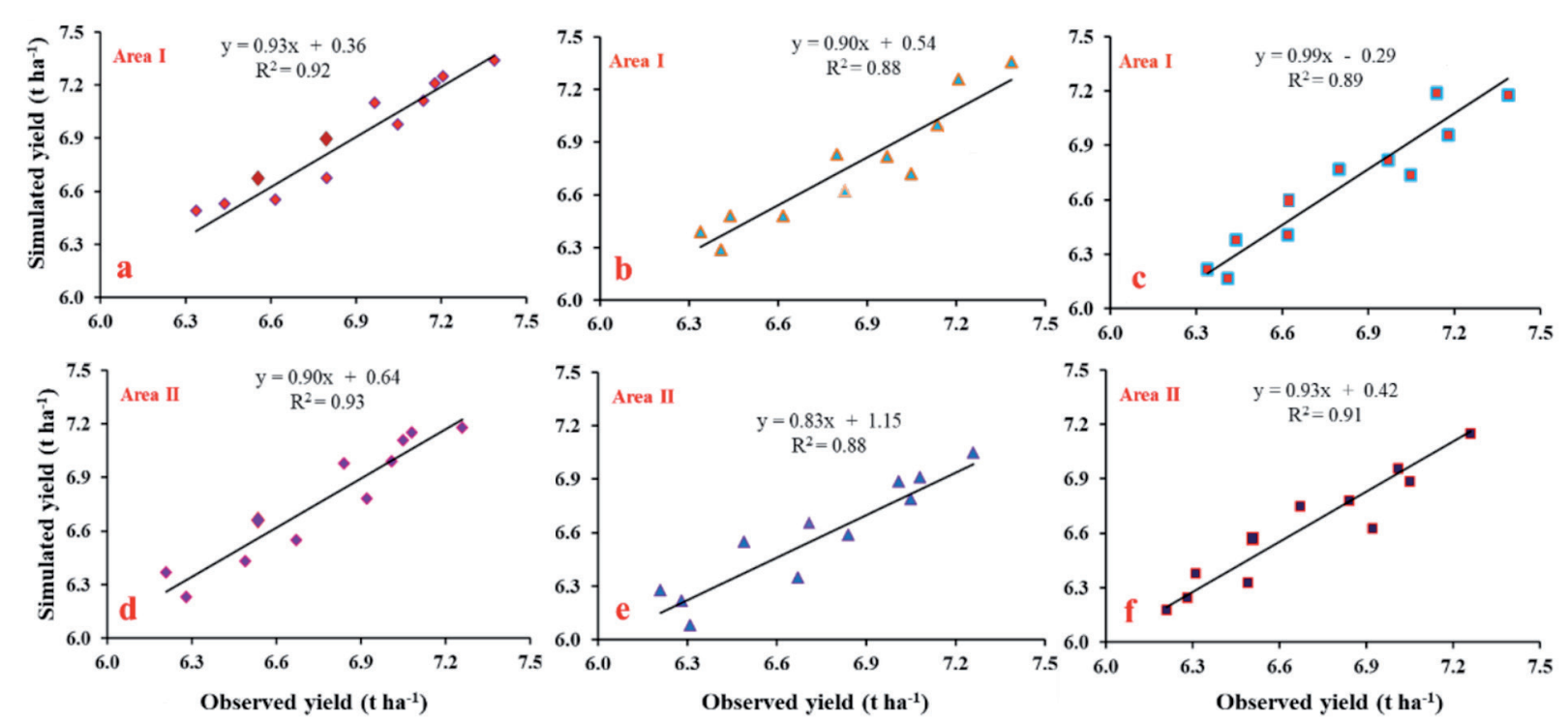

Table 5. Statistics of model performance for the calibration period (2000-2010) and validation period (2011-2018) base on the d index, RMSE and $\mathbf{R}^{2}$.

\begin{tabular}{lcccccccc}
\hline & & \multicolumn{3}{c}{ Calibration period (2000-2010) } & & \multicolumn{3}{c}{ Validation period (2011-2018) } \\
Area & Crop & $\mathrm{d}$ & RMSE & $\mathrm{R}^{2}$ & & $\mathrm{~d}$ & RMSE & $\mathrm{R}^{2}$ \\
\hline \multirow{2}{*}{ Area I } & WS & 0.91 & 0.18 & 0.92 & & 0.89 & 0.19 & 0.95 \\
& SA & 0.85 & 0.36 & 0.88 & & 0.86 & 0.31 & 0.91 \\
& AW & 0.87 & 0.27 & 0.89 & & 0.84 & 0.28 & 0.93 \\
\multirow{3}{*}{ Area II } & WS & 0.86 & 0.20 & 0.93 & & 0.93 & 0.26 & 0.91 \\
& SA & 0.81 & 0.43 & 0.88 & & 0.85 & 0.37 & 0.87 \\
& AW & 0.84 & 0.33 & 0.91 & & 0.82 & 0.30 & 0.90 \\
\hline
\end{tabular}

WS: Winter-spring; SA: summer-autumn; AW: autumn-winter.

\section{Relationship between crop broadcasting calendar and grain yield}

Based on the findings, the grain yield of all rice broadcasting crops can increase if the CBC is changed compared to the baseline. Specifically, the rice yield of the WS and SA cropping seasons can increase up to $6.2 \%$ (approximately $7.4 \mathrm{t} \mathrm{ha}^{-1}$ ) and $5.3 \%$ (reach $6.5 \mathrm{tha}^{-1}$ ) in the two experiment areas (Figure 4) if the CBC is delayed from 7 to $14 \mathrm{~d}$ compared to the baseline (Figures 5a and 5b). While the rice yield of the AW cropping season can achieve $6.7 \mathrm{t} \mathrm{ha}^{-1}$ in the first experiment and $7.1 \mathrm{t} \mathrm{ha}^{-1}$ (increase 6.4\%) in the second experiment if the CBC is shifted $14 \mathrm{~d}$ earlier compared to the baseline (Figure 5c). The simulated results also show that the grain yield of the AW cropping season can achieve up to the optimal level if the rice seeds are broadcasted on 5 to 10 September (Table 6). The results of the study are consistent with a study previously published by Deb et al. (2016). Their results showed that the forward and backward shifts in the crop broadcasting calendar to be beneficial to enhance the crop yield under the ICC. 
Figure 4. Comparison of simulated and observed grain yield of the winter-spring (a), summer-autumn (b), autumn-winter (c) cropping seasons in the first experiment and winter-spring (d), summer-autumn (e), autumn-winter (f) cropping seasons in the second experiment for the model calibration during period 2011-2018.
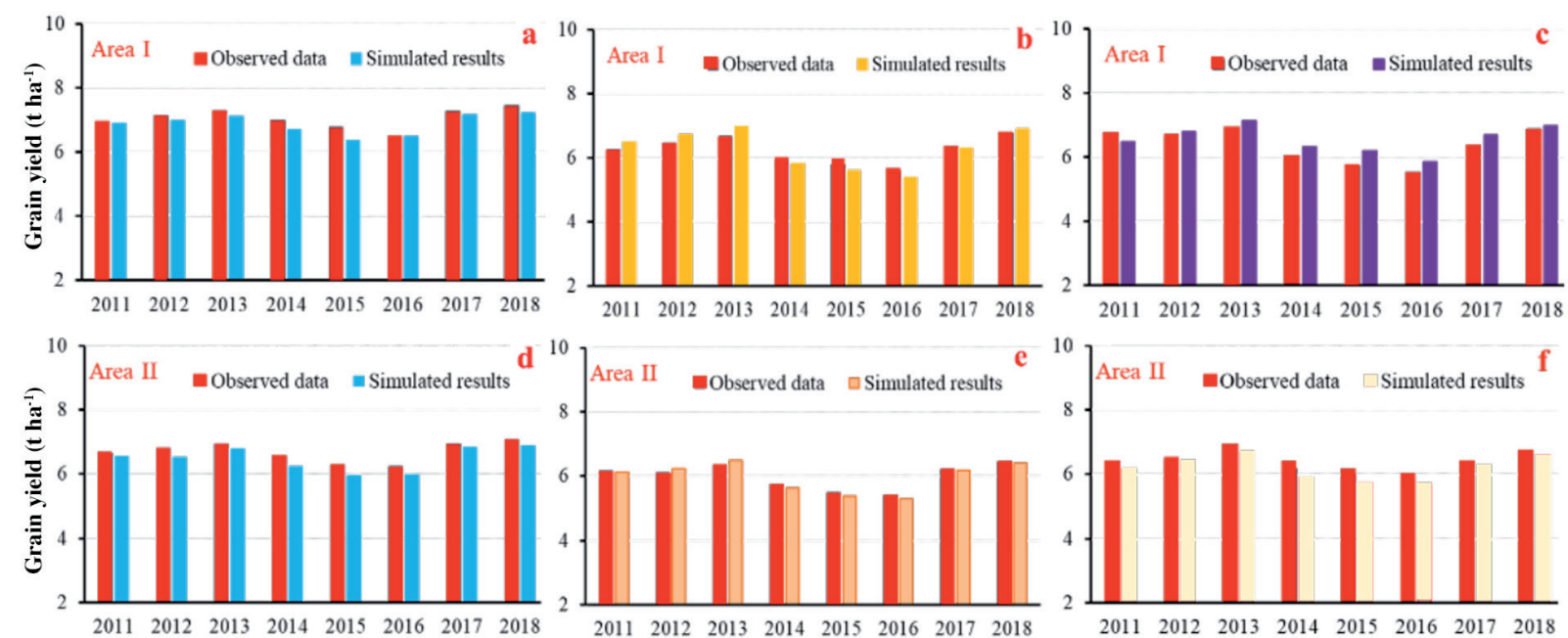

Figure 5. Change in grain yields with different broadcasting calendars of the winter-spring (a), summer-autumn (b), autumn-winter (c) cropping seasons in the two experiment areas with error bars show the change in grain yield due to the shift of the crop broadcasting calendars.

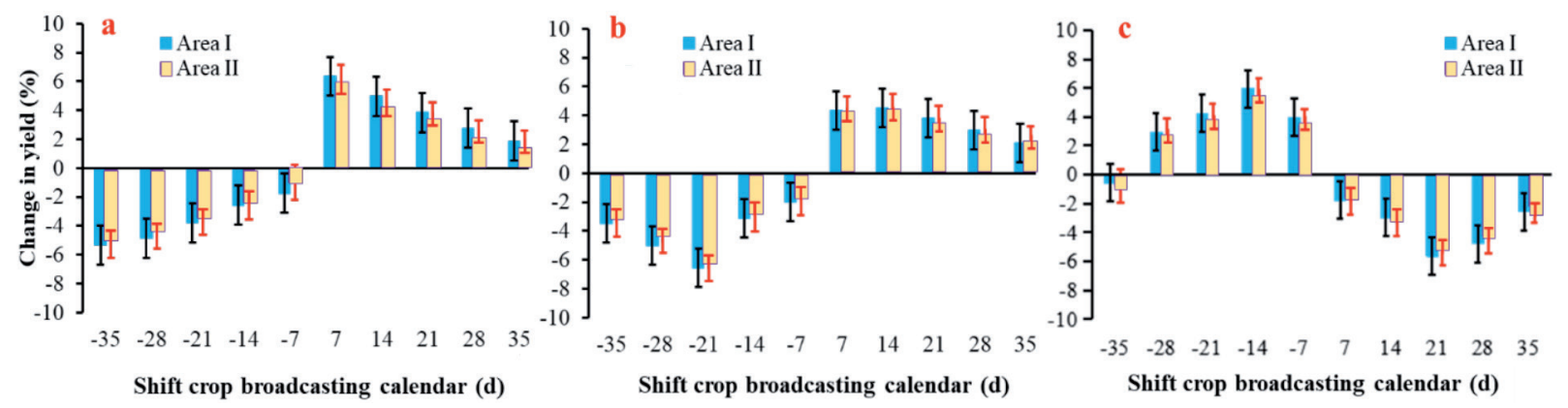

Table 6. Crop yield under shift in the crop broadcasting calendars compared to the baseline for the winter-spring (WS), summer-autumn (SA) and autumn-winter (AW) cropping seasons.

\begin{tabular}{|c|c|c|c|c|c|c|c|c|c|c|c|c|}
\hline \multirow[b]{3}{*}{ Area } & \multirow[b]{3}{*}{ Crop } & \multicolumn{11}{|c|}{ Grain yield with the difference in broadcasting dates } \\
\hline & & \multicolumn{5}{|c|}{ Backward (d) } & \multirow[b]{2}{*}{ Current } & \multicolumn{5}{|c|}{ Forward (d) } \\
\hline & & -35 & -28 & -21 & -14 & -7 & & 7 & 14 & 21 & 28 & 35 \\
\hline & & & & $\mathrm{tha}^{-1}$ & & $\overline{ }$ & $\mathrm{t} \mathrm{ha}^{-1}$ & & & $\mathrm{tha}^{-1}$ & & \\
\hline \multirow[t]{3}{*}{ Area I } & WS & 6.3 & 6.5 & 6.4 & 6.6 & 6.7 & 6.8 & 7.4 & 7.2 & 7.2 & 7.0 & 6.9 \\
\hline & SA & 6.0 & 5.8 & 5.8 & 6.0 & 6.1 & 6.3 & 6.5 & 6.5 & 6.5 & 6.4 & 6.3 \\
\hline & AW & 6.5 & 6.7 & 6.7 & 7.0 & 6.7 & 6.5 & 6.5 & 6.4 & 6.2 & 6.3 & 6.4 \\
\hline \multirow[t]{3}{*}{ Area II } & WS & 6.1 & 6.2 & 6.3 & 6.2 & 6.3 & 6.4 & 6.8 & 6.7 & 6.6 & 6.6 & 6.5 \\
\hline & SA & 5.9 & 5.7 & 5.6 & 5.8 & 5.7 & 5.8 & 6.2 & 6.2 & 6.1 & 6.1 & 6.1 \\
\hline & AW & 6.2 & 6.4 & 6.4 & 6.7 & 6.4 & 6.2 & 6.0 & 5.9 & 5.8 & 5.9 & 6.0 \\
\hline
\end{tabular}




\section{CONCLUSIONS}

The study was conducted to define the suitable broadcasting time for rice paddies in the Long Xuyen Quadrilateral in the context of climate change. Based on the findings, the grain yield of the winter-spring and summer-autumn cropping seasons can improve if the crop broadcasting calendars are delayed from 7 to $14 \mathrm{~d}$ while the autumn-winter cropping season will approach a maximum grain yield if the crop broadcasting calendar is shifted $14 \mathrm{~d}$ earlier compared to the baseline. In general, the grain yield of rice paddies in the Long Xuyen Quadrangle can be significantly improved if the crop broadcasting calendars are changed (forward or backward) compared to the baseline. It can assert that the current broadcasting calendar of three rice broadcasting crops in the Long Xuyen Quadrangle is no longer suitable for weather conditions.

\section{ACKNOWLEDGEMENTS}

The author would like to thank the Southern Regional Hydro-Meteorological Center of Vietnam (SRHCV) and Department of Agriculture and Rural Development (ARD) for providing database.

\section{REFERENCES}

Adnan, A.A., Jibrin, J.M., Kamara, A.Y., Abdulrahman, B.L., Shaibu, A.S., and Garba, I.I. 2017. CERES-Maize model for determining the optimum Kontgis dates of early maturing maize varieties in Northern Nigeria. Frontiers in Plant Science 8:1118. doi:10.3389/fpls.2017.01118.

Archontoulis, S.V., Miguez, F.E., and Moore, K.J. 2014. A methodology and an optimization tool to calibrate phenology of short-day species included in the APSIM model: application to soybean. Environmental Modelling and Software 62:465-477.

Asia Pacific Network. 2010. Climate change in Southeast Asia and assessment on impact, vulnerability and adaptation on rice production and water resource. Final Report for APN Project. CRP2008-03CMY-Jintrawet. Asia Pacific Network (APN) for Global Change Research, Kobe, Japan.

Babel, M.S., Deb, P., and Soni, P. 2019. Performance evaluation of AquaCrop and DSSAT-CERES for maize under different irrigation and manure application rates in the Himalayan Region of India. Agricultural Research 8:207-217.

CGIAR-CCAFS SEA. 2016. Assessment report: The drought and salinity intrusion in the Mekong River Delta of Vietnam. CGIAR Research Program on Climate Change, Agriculture and Food Security-Southeast Asia (CCAFS SEA), Hanoi, Vietnam.

Chatterjee, S.K., Banerjee, S., and Bose, M.M. 2012. Climate change impact on crop water requirement in Ganga river basin, West Bengal, India. $3^{\text {rd }}$ International Conference on Biology, Environment and Chemistry, Bangkok. 24-25 November. Chemical, Biological and Environmental Engineering (CBEE), Corvallis, Oregon, USA. International Proceedings of Chemical, Biological and Environmental Engineering (IPCBEE) 46:17-20. doi:10.7763/ipcbee.2012.V46.4.

Cheng, Z., Meng, J., Qiao, Y., Wang, Y., Dong, W., and Han, Y. 2018. Preliminary study of soil available nutrient simulation using a modified WOFOST model and time-series remote sensing observations. Remote Sensing 10(1):64. doi:10.3390/rs 10010064 .

Deb, P., Tran, D.A., and Udmale, P.D. 2016. Assessment of the impacts of climate change and brackish irrigation water on rice productivity and evaluation of adaptation measures in Ca Mau province, Vietnam. Theoretical and Applied Climatology 125(3-4):641-656.

Dharmarathna, W.R.S.S., Herath, S., and Weerakoon, S.B. 2014. Changing the planting date as a climate change adaptation strategy for rice production in Kurunegala district, Sri Lanka. Sustainability Science 9(1):103-111.

FAO. 2015. AquaCrop new features and updates version 5.0. October 2015. Food and Agriculture Organization (FAO), Rome, Italy.

Jaliya, M.M., Falaki, A.M., Mahmud, M., and Sani, Y.A. 2008. Effect of sowing date and NPK fertilizer rate on yield and yield components of quality protein maize (Zea mays L.) International Journal of Agriculture and Biology 3:23-29.

Jibrin, M.J., Kamara, A.Y., and Friday, E. 2012. Simulating planting date and cultivar effect on dryland maize production using CERES maize model. African Journal of Agricultural Research 7:5530-5536.

Jin, X.L., Feng, H.K., Zhu, X.K., Li, Z.H., Song, S.N., Song, X.Y., et al. 2014. Assessment of the AquaCrop model for use in simulation of irrigated winter wheat canopy cover, biomass, and grain yield in the North China Plain. PLOS ONE 9(1):e86938.

Kamara, A.Y., Friday, E., David, C., and Lucky, O. 2009. Planting date and cultivar effects on dryland corn production. Agronomy Journal 101:91-98. 
Khov, S., Vote, C., Hornbuckle, J., Inthavong, I., Oeurng, C., Sengxua, P., et al. 2017. Calibration and validation of AquaCrop for irrigated peanut (Arachis hypogaea) in lowland rice systems of southern Laos. p. 223-229. In Syme, G., Hatton MacDonald, D., Fulton, B., and Piantadosi, J. (eds.) MODSIM2017, 22 ${ }^{\text {nd }}$ International Congress on Modelling and Simulation, Hobart, Tasmania, Australia. 3-8 December. Modelling and Simulation Society of Australia and New Zealand (MSSANZ), Canberra, Australia. https://doi.org/10.36334/modsim.2017.B1.Khov.

Kim, H.Y., Ko, J., Kang, S., and Tenhunen, J. 2013. Impacts of climate change on paddy rice yield in a temperate climate. Global Change Biology 19:548-562.

Kontgis, C., Schneider, A., Ozdogan, M., Kucharik, C., Pham, V.D.T., Nguyen, H.D., et al. 2019. Climate change impacts on rice productivity in the Mekong River Delta. Applied Geography 102:71-83.

Kotir, J.H. 2011. Climate change and variability in sub-Saharan Africa: a review of current and future trends and impacts on agriculture and food security. Environment Development and Sustainability 13(3):587-605.

Lee, S.K., and Dang, T.A. 2019a. Predicting the water use-demand as a climate change adaptation strategy for rice planting crops in the Long Xuyen Quadrangle Delta. Paddy and Water Environment 17:561-570. https://doi.org/10.1007/s10333-018-00686-y.

Lee, S.K., and Dang, T.A. 2019b. Calibration and validation of the FAO-AquaCrop Model for cassava in the Dong Xuan cultivation area of Phu Yen province using irrigation rainfall. Research on Crops 20(3):555-562.

Lee, S.K., and Dang, T.A. 2019c. Spatio-temporal variations in meteorology drought over the Mekong River Delta of Vietnam in the recent decades. Paddy and Water Environment 17:35-44.

Lee and Dang 2020. Extreme rainfall trends over the Mekong Delta under the impacts of climate change. International Journal of Climate Change Strategies and Management 12(5) ahead-of-print. https://doi.org/10.1108/IJCCSM-04-2020-0032.

Mainuddin, M., Kirby, M., and Hoanh, C.T. 2013. Impact of climate change on rainfed rice and options for adaptation in the lower Mekong Basin. Natural Hazards 66(2):905-938.

MNRE. 2016. Climate change scenarios and sea level rise for Vietnam. Climate change and sea level rise scenarios for Viet Nam. Ministry of Natural Resources and Environment (MNRE), Ha Noi, Vietnam.

Oyeogbe, I.A., and Oluwasemire, K.O. 2013. Evaluation of SOILWAT model for predicting soil water characteristics in southwestern Nigeria. International Journal of Soil Science 8(2):58-67.

Saab, M.T.A., Todorovic, M., and Albrizio, R. 2015. Comparing AquaCrop and CropSyst models in simulating barley growth and yield under different water and nitrogen regimes. Does calibration year influence the performance of crop growth models? Agricultural Water Management 147:21-33.

Silvestro, P.C., Pignatti, S., Yang, H., Yang, G., Pascucci, S., Castaldi, F., et al. 2017. Sensitivity analysis of the Aquacrop and SAFYE crop models for the assessment of water limited winter wheat yield in regional scale applications. PLOS ONE 12(11):e0187485.

Steduto, P., Hsiao, T.C., Raes, D., and Fereres, E. 2009. AquaCrop-The FAO crop model to simulate yield response to water: I. Concepts and underlying principles. Agronomy Journal 101(3):426-437.

Vu, D.T., Yamada, T., and Ishidaira, H. 2018. Assessing the impact of sea level rise due to climate change on seawater intrusion in Mekong Delta, Vietnam. Water Science and Technology 77(6):wst2018038. https://doi.org/10.2166/wst.2018.038.

Wang, Q.G., Chun, J.A., Lee, W.S., Li, S., and Seng, V. 2017. Shifting planting dates and fertilizer application rates as climate change adaptation strategies for two rice cultivars in Cambodia. Journal of Climate Change Research 8(3):187-199.

Yue, Y., Li, J., Ye, X., Wang, Z.Q., Zhu, A.X., and Wang, J.A. 2015. An EPIC model-based vulnerability assessment of wheat subject to drought. Natural Hazards 78(3):1629-1652. 